\title{
Early gastric cancer: diagnosis, staging, and clinical impact. Evaluation of 530 patients. New elements for an updated definition and classification
}

\author{
Luca Saragoni · Paolo Morgagni · Andrea Gardini • \\ Caterina Marfisi • Giovanni Vittimberga • \\ Domenico Garcea $\cdot$ Emanuela Scarpi
}

Received: 23 June 2012/ Accepted: 23 December 2012/Published online: 20 February 2013

(C) The International Gastric Cancer Association and The Japanese Gastric Cancer Association 2013

\begin{abstract}
Background The prevention and early diagnosis of gastric cancer permit clinicians to discover the tumor in the initial phase, during which time it can be completely eradicated, endoscopically or surgically. Since Murakami gave the definition of early gastric cancer (EGC) in 1971, many authors have identified various subtypes of EGC with different morphological characteristics and clinical behaviour.

Methods We evaluated retrospectively 530 patients: the median follow-up time was 10.4 months (range 0.3-29.2). All tumors were classified according to the macroscopic and microscopic criteria proposed by the Japanese Society of Gastroenterology and Endoscopy and Lauren, respectively. The infiltrative growth pattern was evaluated according to Kodama's classification. Only tumor-related death was considered as an endpoint of interest for the survival analysis. Results The overall survival rates of our patients were $94 \%$ (95\% CI, 92-96) and $90 \%$ (95\% CI, 87-93) at 5 and 10 years, respectively. Only 44 patients $(8.3 \%)$ died of the disease. Kodama's type $(p<0.0001)$, lymph node status, both for number and pathological stage according to
\end{abstract}

\footnotetext{
L. Saragoni $(\square)$

Department of Pathology, Hospital G.B. Morgagni-L. Pierantoni, Via C. Forlanini 34, 47121 Forlì, Italy

e-mail: 1.saragoni@ausl.fo.it

P. Morgagni - A. Gardini · C. Marfisi · G. Vittimberga ·

D. Garcea

The 1st Division of General Surgery, Hospital G.B. Morgagni-L. Pierantoni, Via C. Forlanini 34, 47121 Forlì, Italy

E. Scarpi

Biostatistics and Clinical Trials Unit, IRCCS Istituto Scientifico Romagnolo per lo Studio e la Cura dei Tumori (I.R.S.T.), Meldola, FC, Italy
}

the 7th Edition of TNM $(p<0.0001)$, and depth of infiltration $(p=0.0006)$ were significant prognostic factors in univariate analysis. The multivariate analysis identified Kodama's PENA type (HR, 3.91; $95 \%$ CI, 2.08-7.33; $p<0.0001)$ and lymph node status for more than three positive nodes versus negative nodes (HR, 12.78; $95 \% \mathrm{CI}$, $5.37-30.43 ; p<0.0001)$ as the only independent prognostic factors in our series.

Conclusion Lymph node status, especially when more than three lymph nodes are involved, is the most important prognostic factor in EGC. However, it is also important to evaluate the infiltrative growth pattern of the cancers in their early phase according to Kodama's classification, considering PEN A type lesions to be more aggressive than the other EGC types. Then, we propose new elements for an updated definition and classification of EGC, with an important clinical impact on the treatment of patients.

Keywords EGC $\cdot$ Prognosis $\cdot$ Treatment

\section{Introduction}

The term "early gastric cancer" (EGC), defined in 1971 by the Japanese Society of Gastroenterology and Endoscopy [1] as carcinoma limited to gastric mucosa and or submucosa regardless of lymph node status, has continued to spark controversies over the years [2-4].

Numerous studies have focused on key parameters that could be associated with the risk of lymph node metastases or treatment failure in EGC [3-7].

Better knowledge and increased numbers of EGC have resulted from the improvement and diffusion of endoscopies and the introduction of new technologies, such as chromoendoscopy and magnifying endoscopy. 
In our area, which has a high incidence of gastric cancer, EGC represents about $25 \%$ of all gastric cancers treated surgically. This percentage of "early lesions" is considered to be really good for Western countries, even though not yet comparable to those of Eastern countries, where EGCs represent more than $50 \%$ of all tumors [8]. The presence of an active mass screening program [9] and different classification systems for gastrointestinal dysplasia and gastric carcinoma in Eastern and Western countries [10-16] still accounts for significant differences in the detection of EGC.

In particular, the experience we gained by evaluating 530 patients affected by EGC has demonstrated that there is a significantly worse survival probability in node-positive and PEN A type patients, as we suggested in our previous reports [5-7].

According to Kodama's classification, the abbreviation PEN stands for penetrating and indicates a lesion with a diameter of less than $4 \mathrm{~cm}$ that invades the submucosa in a widely penetrating fashion. In particular, PEN A type EGC represents a subgroup of tumors that invades the submucosa extensively, with nodular masses, causing the complete destruction of the muscularis mucosae.

We were also able to demonstrate the important clinical impact of size, depth of infiltration, and histological type of tumors, with special reference to the distribution of lymph node metastases.

According to our data, which identified subgroups of patients with a different prognosis, we propose to introduce a revised definition of EGC, considering as "early" only those tumors limited to the mucosal layer or, at least, minimally invading submucosa, considering minimally invading the EGCs with a depth of submucosal infiltration less than $500 \mu \mathrm{m}$ (SM1 tumors), and without lymph node metastases. Such a consideration is prompted, not only by the prognostic behaviour of the different kinds of tumors, but also by the possibility of identifying the patients who can be safely and radically treated with endoscopic resection, defined by evaluation of the endoscopic specimen, according to Japanese guidelines.

\section{Subjects and methods}

We analyzed retrospectively the data from 530 patients who underwent surgery at G.B. Morgagni-L. Pierantoni Hospital of Forlì (Italy) between 1976 and 2006. The EGC/ advanced cancer ratio was $25 \%$.

All the patients underwent a subtotal or total gastrectomy with a D2 lymphadenectomy, according to Japanese guidelines. The EGCs were classified according to macroscopic and microscopic criteria proposed by the Japanese Society of Gastroenterology and Endoscopy (JSGE) and Lauren, respectively [17, 18]. The JSGE criteria divided the EGCs into type I (polypoid), type IIa (elevated), type IIb (flat), type IIc (depressed), and type III (excavated). From the histological point of view, two main categories exist, designated as intestinal and diffuse by Lauren. A third group includes mixed carcinomas. The classification of Kodama [19] was used to define the extent and histological growth pattern of penetration of the cancer (Table 1). According to this classification, the super (superficial spreading) type is a tumor with a diameter of more than $4 \mathrm{~cm}$, either confined to the mucosa (Super M) or with minimal invasion of the submucosa (Super SM); small mucosal type is a carcinoma with a diameter of less than $4 \mathrm{~cm}$, with (small mucosal SM) or without (small mucosal $\mathrm{M}$ ) a minimal submucosal invasion; and PEN (penetrating) type is a lesion with a diameter of less than $4 \mathrm{~cm}$, which invades the submucosa widely. This type is further subdivided into two subgroups, according to the type of infiltration of the muscularis mucosae: PEN A type, which invades the submucosa extensively with nodular masses and completely destroys the muscularis mucosae, and PEN B type, which grows infiltratively, with fenestration of the muscularis mucosae. The resected stomachs were opened along the greater curvature, pinned to a wooden plate, and fixed in $10 \%$ buffered formalin. The tumors in the surrounding gastric wall were cut into several slices, mainly parallel to the lesser curvature, at intervals of $4-5 \mathrm{~mm}$. Sections $5 \mu \mathrm{m}$

Table 1 Types of early gastric cancers (EGCs) and their distribution according to Kodama

\begin{tabular}{llr}
\hline Kodama's types & & Total (\%) \\
\hline Small mucosal, M & Intramucosal EGCs measuring less than $4 \mathrm{~cm}$ & $250(47.2 \%)$ \\
Small mucosal, SM & Intramucosal EGCs minimally invading submucosa measuring less than $4 \mathrm{~cm}$ & $89(16.8 \%)$ \\
Supermucosal, M & Intramucosal EGCs measuring more than $4 \mathrm{~cm}$ & $17(3.2 \%)$ \\
Supermucosal, SM & Intramucosal EGCs minimally invading submucosa measuring more than $4 \mathrm{~cm}$ & $28(5.3 \%)$ \\
PEN (penetrating), A & EGCs massively invading submucosa with nodular pattern measuring less than $4 \mathrm{~cm}$ & $104(19.6 \%)$ \\
PEN (penetrating), B & EGCs massively invading submucosa with saw teeth pattern measuring less than $4 \mathrm{~cm}$ & $41(7.7 \%)$ \\
Missing & & $1(0.2 \%)$ \\
Mixed & Penetrating types (A or B) measuring more than $4 \mathrm{~cm}$ & $0(0.0 \%)$ \\
\hline
\end{tabular}


thick, embedded in paraffin, were prepared from each slide for histological examination. The WHO classification was used to define the degree of tumor differentiation [20]. Lymph nodes were completely included in paraffin blocks from which two different microtomic levels at a distance of $200 \mu \mathrm{m}$ were cut. A maximum number of five lymph nodes was included in each paraffin block. Then, two slides including slices of the lymph nodes cut at the two different levels obtained from each paraffin block were stained. The median follow-up was 10.4 months (range, 0.3-29.2 months).

Overall survival (OS) was calculated as the period from the date of surgical treatment until death.

Only tumor-related deaths were considered as an endpoint of interest for the survival analysis.

Five- and 10-year OS probability and the $95 \%$ confidence interval (95\% CI) were obtained using KaplanMeier estimates [21]. The null hypothesis concerning the different impact of each variable on clinical outcome was tested in univariate analysis by a log-rank test [22].

The prognostic effect of each variable was evaluated in univariate and multivariate analyses using a Cox regression model [23].

The chi-square test was employed to define the association between the subgroups of pathological and clinical criteria examined.

All $p$ values were based on two-sided testing, and statistical analyses were carried out using SAS statistical software [24].

\section{Results}

Among our patients, 305 were men and 225 women. About $50 \%$ of the EGCs were located in the lower third of the stomach. We missed some topographic data, especially in the oldest cases. Almost all cases were monofocal $(94.3 \%)$. Intramucosal and submucosal infiltration were observed with similar frequency. Macroscopic IIc and III types were found in more than $70 \%$ of all tumors; small mucosal M Kodama's type represented about $50 \%$ of all lesions (Table 1). Histologically, the intestinal type was the most frequent finding (78.7\%), according to Lauren's classification. Lymph node metastases affected 78 patients (14.7\%).

The lymph node status was significantly associated with histological type $(p<0.0001)$, infiltration of the wall $(p<0.0001)$, tumor size $(p=0.0004)$, and Kodama's type $(p<0.0001)$. In particular, the incidence of lymph node metastases was $31.7 \%$ for Kodama's PEN A types, $30.2 \%$ for histological diffuse types, $25.8 \%$ for submucosal lesions, and $20.8 \%$ for tumors larger than $2 \mathrm{~cm}$ (Table 2).
Table 2 Distribution of lymph node metastases

\begin{tabular}{|c|c|c|c|}
\hline & $\begin{array}{l}N-\text {, Numbers } \\
\text { of patients } \\
(\%)\end{array}$ & $\begin{array}{l}N+, \text { Numbers } \\
\text { of patients } \\
(\%)\end{array}$ & $p$ value \\
\hline \multicolumn{4}{|l|}{ Kodama } \\
\hline PEN A & $71(15.7)$ & $33(42.3)$ & \\
\hline Not PEN A & $380(84.3)$ & $45(57.7)$ & $<0.0001$ \\
\hline \multicolumn{4}{|c|}{ Histotypes (Lauren) } \\
\hline Intestinal & $372(89.4)$ & $46(70.8)$ & \\
\hline Diffuse & $44(10.6)$ & $19(29.2)$ & $<0.0001$ \\
\hline \multicolumn{4}{|c|}{ Macrotypes (JSGE) } \\
\hline I-IIa-IIb & $130(28.8)$ & $14(18.2)$ & \\
\hline IIc-III & $321(71.2)$ & $63(81.8)$ & 0.109 \\
\hline \multicolumn{4}{|l|}{ Infiltration } \\
\hline Mucosal & $288(63.7)$ & $20(26.0)$ & \\
\hline Submucosal & $164(36.3)$ & $57(74.0)$ & $<0.0001$ \\
\hline \multicolumn{4}{|l|}{ Size } \\
\hline$\leq 2 \mathrm{~cm}$ & $251(55.9)$ & $26(33.3)$ & \\
\hline$>2 \mathrm{~cm}$ & $198(44.1)$ & $52(66.7)$ & 0.0004 \\
\hline
\end{tabular}

Tumor-related deaths totaled $8.3 \%$ (44 patients). The survival rate was $94 \%(95 \% \mathrm{CI}, 92-96)$ at 5 years and $90 \%$ (95\% CI, 87-93) at 10 years.

On univariate analysis, a significantly lower survival rate was observed for patients with submucosal tumours $(p=0.0006)$, PEN A type disease $(p<0.0001)$, and nodepositive cancers $(p=0.0002)$ (Table 3$)$. In particular, a significantly worse prognosis was demonstrated for patients with more than three metastatic lymph nodes $(p<0.0001)$. We have no information regarding a few older tumors.

Moreover, on multivariate analysis (Table 4), EGC patients with more than three positive nodes had a risk of death about 13 times higher than that of patients with negative lymph nodes (HR, 12.78; $95 \%$ CI, 5.37-30.43; $p<0.0001$ ), and EGC PEN A type patients had a 4-fold-higher death risk (HR, 3.91; $95 \%$ CI, 2.08-7.33; $p<0.0001$ ).

No significantly worse prognosis was observed for patients affected by Kodama's types other than PEN A (Table 5).

These results suggest that the biological behavior of EGCs depends tightly on the lymph node status and histological growth pattern according to Kodama's criteria. So, the patients with these findings must be considered affected by an advanced gastric cancer, instead of by an "early lesion," and then considered for standard surgical treatment.

Among the 78 node-positive patients, 57 were affected by submucosal tumors and only 20 by intramucosal EGCs. One patient was lost from follow-up. Among the 20 intramucosal tumors, 11 lesions had a diameter of less than $2 \mathrm{~cm}$ and 9 measured more than $2 \mathrm{~cm}$. Only 2 of the 11 smaller EGCs were well-differentiated tumors (grade 1 according to WHO classification), and both were ulcerated. 
Table 3 Univariate analysis: 5- and 10-year survival probability, hazard ratio (HR), and relative $95 \%$ confidence interval (95\% CI)

\begin{tabular}{|c|c|c|c|c|c|c|c|}
\hline & $\begin{array}{l}\text { Number of } \\
\text { patients }\end{array}$ & $\begin{array}{l}\text { Number of } \\
\text { events }\end{array}$ & $\begin{array}{l}\text { Five-year \% } \\
(95 \% \text { CI })\end{array}$ & $\begin{array}{l}\text { Ten-year \% } \\
(95 \% \text { CI })\end{array}$ & $\begin{array}{l}p \text { value } \\
\text { (log-rank) }\end{array}$ & $\operatorname{HR}(95 \% \mathrm{CI})$ & $\begin{array}{l}p \text { value } \\
\text { (Cox) }\end{array}$ \\
\hline Overall & 530 & 44 & 94 (92-96) & 90 (87-93) & - & - & - \\
\hline \multicolumn{8}{|l|}{ Depth } \\
\hline Mucosal & 308 & 16 & 97 (95-99) & 95 (92-98) & & 1.00 & \\
\hline Submucosal & 221 & 28 & 89 (85-93) & $83(78-88)$ & 0.0006 & $2.79(1.51-5.16)$ & 0.001 \\
\hline \multicolumn{8}{|l|}{ Size } \\
\hline$\leq 2 \mathrm{~cm}$ & 277 & 18 & 97 (94-100) & 92 (89-95) & & 1.00 & \\
\hline$>2 \mathrm{~cm}$ & 250 & 25 & 91 (87-95) & 88 (83-93) & 0.077 & $1.72(0.94-3.15)$ & 0.080 \\
\hline \multicolumn{8}{|l|}{ Kodama } \\
\hline Not PEN A & 425 & 23 & 97 (95-99) & $94(92-96)$ & & 1.00 & \\
\hline PEN A & 104 & 21 & $83(76-90)$ & $73(63-83)$ & $<0.0001$ & $4.68(2.58-8.46)$ & $<0.0001$ \\
\hline \multicolumn{8}{|l|}{ Nodes } \\
\hline Negative & 452 & 30 & $96(94-98)$ & $92(89-95)$ & & 1.00 & \\
\hline Positive & 78 & 14 & $82(73-91)$ & $78(68-88)$ & 0.0002 & $3.17(1.68-5.99)$ & 0.0004 \\
\hline \multicolumn{8}{|l|}{$N-$ nodes +} \\
\hline 0 & 452 & 30 & $96(94-98)$ & $92(89-95)$ & & 1.00 & \\
\hline $1-3$ & 59 & 6 & $90(82-98)$ & 87 (77-97) & & $1.62(0.67-3.90)$ & 0.280 \\
\hline$>3$ & 19 & 8 & $53(27-79)$ & $46(19-72)$ & $<0.0001$ & $11.44(5.22-25.09)$ & $<0.0001$ \\
\hline \multicolumn{8}{|c|}{ pN (TNM 7th Edition) } \\
\hline$N-$ & 452 & 30 & $96(94-98)$ & $92(89-95)$ & & 1.00 & \\
\hline$N 1$ & 49 & 4 & $93(85-100)$ & $89(78-100)$ & & $1.28(0.45-3.64)$ & 0.640 \\
\hline$N 2$ & 21 & 5 & 77 (57-97) & $70(47-93)$ & & $4.95(1.92-12.78)$ & 0.0009 \\
\hline$N 3 \mathrm{a}$ & 7 & 4 & $34(0-73)$ & $34(0-73)$ & & $16.24(5.69-46.39)$ & $<0.0001$ \\
\hline$N 3 b$ & 1 & 1 & 0 & 0 & $<0.0001$ & $48.14(6.22-372.74)$ & 0.0002 \\
\hline
\end{tabular}

Table 4 Multivariate analysis adjusted for sex and age (continuous)

\begin{tabular}{lllr}
\hline Factor & & HR $(95 \% \mathrm{CI})$ & $p$ value \\
\hline Kodama & PEN A versus not PEN A & $3.91(2.08-7.33)$ & $<0.0001$ \\
$N$ & $N+>3$ versus $N-/ N+1-3$ & $12.78(5.37-30.43)$ & $<0.0001$ \\
\hline
\end{tabular}

Table 5 5- and 10-year survival probability for Kodama's types

\begin{tabular}{lllll}
\hline & $\begin{array}{l}\text { Number } \\
\text { of patients }\end{array}$ & $\begin{array}{l}\text { Number of } \\
\text { events }\end{array}$ & Five-year \% (95 \% CI) & Ten-year \% (95 \% CI) $p$ value (log-rank) \\
\hline Kodama & & & & \\
Small mucosal M & 250 & 14 & $97(95-99)$ & $95(91-99)$ \\
Small mucosal SM & 89 & 6 & $95(89-100)$ & $91(84-98)$ \\
Supermucosal M & 17 & 0 & 100 & $95(86-100)$ \\
Supermucosal SM & 28 & 1 & $95(86-100)$ & $94(87-100)$ \\
PEN B & 41 & 2 & $97(92-100)$ & $73(63-83)$ \\
PEN A & 104 & 21 & $83(76-90)$ & $<0.0001$ \\
\hline
\end{tabular}

\section{Discussion}

The improvement and diffusion of endoscopic techniques and better knowledge of the problem have led to a significant increase in early gastric cancers (EGC) over the past few years. In the Forlì area, EGC represents about $25 \%$ of all resected gastric cancers [5, 6]. Now, our experience with EGC allows the endoscopic treatment of some of these tumors, when EGC characteristics exclude lymph node involvement. In particular, according to our results, 
Kodama's PEN A types, histological diffuse, submucosal tumors, and lesions larger than $2 \mathrm{~cm}$ are all conditions with a higher risk of lymph node metastases. All these aspects must be confirmed by pathologists after the endoscopic dissection. In fact, endoscopic mucosal resection (EMR)/ endoscopic submucosal resection (ESD) has a diagnostic value as its primary endpoint. Then, if none of the aforementioned unfavorable histological characteristics is detected, the endoscopic resection can be considered the definitive and safe treatment of the tumor, as some authors previously demonstrated [25-27]. Endoscopic resection of early gastric cancers with no risk of lymph node metastases is a standard technique in Japan, probably because of the high incidence of gastric cancer and the fact that more than half of Japanese gastric neoplasms are diagnosed at an early stage. This finding is also the result of the existence of different classification systems for gastrointestinal dysplasia and gastric carcinoma in Western and Eastern countries [10-16]. Recently endoscopic mucosal resection (EMR) has been increasingly accepted and regularly used in Western countries. Despite this, however, so far a wide European experience that could give us significant and useful information to be clinically applied and then compared to the data of Japanese authors has not been recorded. The latter have defined the criteria that must be evaluated by pathologists on the endoscopic specimen to consider EMR safe and radical as a treatment of EGC [2834]. These criteria have been changed in the past 10 years, also because of the introduction of the new endoscopic techniques, such as endoscopic submucosal resection (ESD), which allows Japanese endoscopists to remove radically bigger lesions [25, 35-38]. Tumor conditions suitable only for endoscopic resection as a treatment of choice to remove the lesions completely $[25,31]$ are neoplasias less than $2 \mathrm{~cm}$, histologically well differentiated, limited to the mucosa, and without ulcer and lymphatic/ vessel invasion. When these conditions are all met, the endoscopic treatment of the tumors can be considered safe. On the other hand, if only one of the unfavorable parameters occurs, the patient must be treated surgically because of the significant risk of lymph node metastases. This consideration is true also in our series: among the 78 nodepositive patients there were 20 intramucosal EGCs, each of which showed at least one of the unfavorable histological parameters.

The retrospective analysis of our series of EGCs showed that tumor size larger than $2 \mathrm{~cm}(66.7 \%)$, infiltration of the submucosa $(74.0 \%)$, diffuse histological type $(29.2 \%)$, and Kodama's PEN A type $(42.3 \%)$ were important and significant risk factors for lymph node metastases. Moreover, univariate analysis demonstrated that patients with submucosal lesions $(89 \%$ at 5 years and $83 \%$ at 10 years), Kodama's PEN A type cancers ( $83 \%$ at 5 years and $73 \%$ at 10 years), lymph node metastases (82\% at 5 years and $78 \%$ at 10 years) and more than three positive lymph nodes (53\% at 5 years and $46 \%$ at 10 years) had a significantly worse prognosis.

This knowledge permitted us to identify subgroups of EGC patients affected by different stages of the disease, strictly linked to clinical behavior, prognosis, and then the treatment. The depth of wall invasion has been considered the most important prognostic factor since Murakami introduced the definition of early gastric cancer in 1971 .

Subsequent clinical evidence, however, has consistently indicated nodal involvement as the most important prognostic parameter, so that only cancers without nodal invasion were considered as early neoplasms [39, 40]. By taking this into consideration, some authors have demonstrated that the disease in patients with gastric cancer without lymph node metastases, but with invasion of the muscularis propria, behaved in a similar way to the disease in conventional EGC patients [41].

We previously demonstrated that both the invasion of submucosa and the presence of lymph node metastases must be considered unfavorable prognostic factors in EGC patients, suggesting modification of the definition of EGC [5, 6].

Apart from our previous observations, few reports have suggested upgrading the definition of EGC by identifying subgroups of patients with nodal metastases, characterized by a worse prognosis [3, 39, 40]. According to these authors, infiltration into the wall was not so important as lymph node status for establishing the biological behavior and prognosis of the tumor. Again, in our current larger series, we have shown that lymph node metastases and Kodama's PEN A type still remain independent prognostic factors; moreover, the massive infiltration of the submucosa in EGC patients means a higher risk of lymph node metastases. For this reason, we propose to reconsider the definition of EGC as Murakami conceived it in 1971. According to our experience, it should be more appropriate to call "early" those gastric cancers that are limited to the mucosa, or at least do not infiltrate the submucosal layer massively, and have no lymph node metastases.

\section{References}

1. Murakami T. Pathomorphological diagnosis, definition and gross classification of early gastric cancer. Gann Monogr Cancer Res. 1971;11:53-66.

2. Japanese Research Society for Gastric Cancer. The general rules for gastric cancer study in surgery and pathology. Jpn J Surg. 1981;11:127-39.

3. Abe S, Yoshimura H, Nagaoka S, Monden N, Kinugasa S, Nagasue N, et al. Long-term results of operation for carcinoma of the stomach in T1/T2 stages: critical evaluation of the concept of 
early carcinoma of the stomach. J Am Coll Surg. 1995;181: 389-96.

4. Sano T, Kobori O, Muto T. Lymph node metastasis from gastric cancer: endoscopic resection of tumour. Br J Surg. 1992;79: $241-4$.

5. Folli S, Dente M, Dell'Amore D, Gaudio M, Nanni O, Saragoni L, et al. Early gastric cancer: prognostic factors in 223 patients. Br J Surg. 1995;82:952-6.

6. Saragoni L, Gaudio M, Vio A, Folli S, Nanni O, Saragoni A. Early gastric cancer in the province of Forlì: follow-up of 337 patients in a high risk region for gastric cancer. Oncol Rep. 1998;5:945-8.

7. Saragoni L, Gaudio M, Morgagni P, Folli S, Vio A, Scarpi E, et al. The role of growth patterns, according to Kodama's classification, and lymph node status, as important prognostic factors in early gastric cancer: analysis of 412 cases. Gastric Cancer. 2000;3:134-40.

8. Sano T, Sasako M, Kinoshita T, Maruyama K. Recurrence of early gastric cancer. Follow-up of 1475 patients and review of Japanese literature. Cancer 1993;72:3174-8.

9. Aochi K. Trends in stomach cancer mortality in Japanese women: an evaluation of prevention programs. Third International Gastric Cancer Congress, Seoul (Korea), April 27-30, 1999. Bologna: Monduzzi Editore.

10. Schlemper RJ, Itabashi M, Kato Y, Lewin KJ, Riddell RH, Shimoda $\mathrm{T}$, et al. Differences in diagnostic criteria for gastric carcinoma between Japanese and Western pathologists. Lancet. 1997;349:1725-9.

11. Genta RM, Rugge M. Gastric precancerous lesions: heading for an international consensus. Gut 1999;45(suppl 1):5-8.

12. Kim YI. Definition, classification and epidemiology of dysplasia. Third International Gastric Cancer Congress, Seoul (Korea), April 27-30, 1999. Bologna: Monduzzi Editore.

13. Lauwers GY, Shimizu M, Correa P, Riddell RH, Kato Y, Lewin $\mathrm{KJ}$, et al. Evaluation of gastric biopsies for neoplasia: differences between Japanese and Western pathologists. Am J Surg Pathol. 1999;23:511-8.

14. Lewin KJ. Nomenclature problems of gastrointestinal epithelial neoplasia. Am J Surg Pathol. 1998;22:1043-7.

15. Riddell RH, Iwafuchi M. Problems arising from Eastern and Western classification systems for gastrointestinal dysplasia and carcinoma: are they resolvable? Histopathology. 1998;33:197-202.

16. Rugge M, Farinati F, Di Mario F, Baffe R, Valiante F, Cardin F. Gastric epithelial dysplasia: a prospective multicenter follow-up study from the interdisciplinary group on gastric dysplasia. Hum Pathol. 1991;22:1002-8.

17. Ohta H, Noguchi Y, Takagi K, Nishi M, Kajitani T, Kato Y. Early gastric carcinoma with special reference to macroscopic classification. Cancer. 1987;60:1099-106.

18. Lauren P. The two main histological types of gastric carcinoma: an attempt to reach a histoclinical classification. Acta Pathol Microbiol Scand. 1965;64:31-49.

19. Kodama Y, Inokuchi K, Soejima K, Matsusaka K, Okamura T. Growth patterns and prognosis in early gastric cancer. Superficially spreading and penetrating growth types. Cancer 1983;51:320-6.

20. World Health Organization. Pathology and genetics. In: Bosman FT, Carneiro F, Hruban RH, Theise ND (eds) Tumours of the digestive system, 4th edition. Lyon: IARC Press; 2010.

21. Kaplan EL, Meier P. Non parametric estimation for incomplete observation. J Am Stat Assoc. 1958;53:457-81.
22. Lawless JS. Statistical models and methods for life-time data. New York: Wiley; 1982.

23. Cox DR. Regression models and life tables. J R Stat Soc. 1972;34:187-220.

24. SAS Institute. SAS/STAT User's guide, version 9.3. Cary, NC.

25. Gotoda T, Yamamoto H, Soetikno RM. Endoscopic submucosal dissection of early gastric cancer. J Gastroenterol. 2006;41: 929-42.

26. Kashimura H, Watanabe H, Yoichi Ajioka Y, Nishikura K, Iri T, Asakura H. The risk factors for nodal micrometastasis of submucosal invasive gastric carcinoma with special reference to assessment of the indication for endoscopic treatment. Gastric Cancer. 1999;2:33-9.

27. Gotoda T, Yanagisawa A, Sasako M, Ono H, Nakaneshi Y, Shimoda $\mathrm{T}$, et al. Incidence of lymph node metastasis from early gastric cancer: estimation with a large number of cases at two large centres. Gastric Cancer. 2000;3:219-25.

28. Gotoda T. Endoscopic resection of early gastric cancer: the Japanese perspective. Curr Opin Gastroenterol. 2006;22:561-9.

29. Rembacken BJ, Gotoda T, Fujii T, Axon AT. Endoscopic mucosal resection. Endoscopy. 2001;33:709-18.

30. Soetikno R, Gotoda T, Nakanishi Y, Soehendra N. Endoscopic mucosal resection. Gastrointest Endosc. 2003;57:567-79.

31. Ludwig K, Klautke G, Bernhard J, Weiner R. Minimally invasive and local treatment for mucosal early gastric cancer. Surg Endosc. 2005;19:1362-6.

32. Oda I, Saito D, Tada M, Iishi H, Tanabe S, et al. A multicenter retrospective study of endoscopic resection for early gastric cancer. Gastric Cancer. 2006;9:262-70.

33. Eguchi T, Gotoda T, Oda I, Hamanaka H, Hasuike N, Saito D. Is endoscopic one-piece mucosal resection essential for early gastric cancer? Dig Endosc. 2003;15:113-6.

34. Ono H, Kondo H, Gotoda T, Shirao K, Yamaguchi H, Saito D, et al. Endoscopic mucosal resection for treatment of early gastric cancer. Gut. 2001;48:225-9.

35. Gotoda T, Kondo H, Ono H, Saito Y, Yamaguchi H, Saito D, et al. A new mucosal endoscopic resection procedure using an insulated-tipped electrosurgical knife for rectal flat lesions. Gastrointest Endosc. 1999;50:560-3.

36. Oda I, Gotoda T, Hamanaka H, Eguchi T, Sayto Y, Matsuda T, et al. Endoscopic submucosal dissection for early gastric cancer : technical feasibility, operation time, and complications from a large consecutive series. Dig Endosc. 2005;17:54-8.

37. Yamamoto H, Kawata H, Sunada K, Sasaki A, Nakazawa K, Miyata T, et al. Successful one-piece resection of large superficial tumors in the stomach and colon using sodium hyaluronate and small-caliber-tip transparent hood. Endoscopy. 2003;35:690-4.

38. Oyama T, Kikuchi Y. Aggressive endoscopic mucosal resection in the upper GI tract: hook knife EMR method. Minim Invasive Ther Allied Technol. 2002;11:291-5.

39. Inoue K, Tobe T, Kan N, Nio Y, Sakai M, Takeuchi E, et al. Problems in the definition and treatment of early gastric cancer. Br J Surg. 1991;78:818-21.

40. Kim JP, Hur YS, Yang HK. Lymph node metastasis as a significant prognostic factor in early gastric cancer: analysis of 1136 early cancers. Ann Surg Oncol. 1995;2:308-13.

41. Adachi Y, Masafuni I, Seigo K, Masaki M, Yoshihiko M, Keizo S. Duke's A tumor: new criteria for early gastric cancer. Oncol Rep. 1997;4:1235-8. 